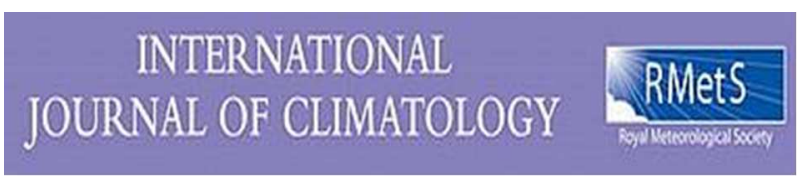

\title{
Interannual Variability of the Onset of the South China Sea Summer Monsoon
}

\begin{tabular}{|r|l|}
\hline Journal: & International Journal of Climatology \\
\hline Manuscript ID: & JOC-13-0508.R2 \\
\hline Wiley - Manuscript type: & Research Article \\
\hline Complete List of Authors: & $\begin{array}{l}\text { Luo, Ming; The Chinese University of Hong Kong, Department of } \\
\text { Geography and Resource Management } \\
\text { Leung, Yee; The Chinese University of Hong Kong, Department of } \\
\text { Geography and Resource Management } \\
\text { Zhang, Wei; The Chinese University of Hong Kong, Department of } \\
\text { Geography and Resource Management } \\
\text { Graf, Hans; University of Cambridge, Centre for Atmospheric Sciences } \\
\text { Herzog, Michael; University of Cambridge, Centre for Atmospheric Sciences }\end{array}$ \\
\hline Keywords: & $\begin{array}{l}\text { South China Sea summer monsoon, monsoon onset, sea surface } \\
\text { temperature, land surface temperature, ENSO }\end{array}$ \\
\hline
\end{tabular}

\section{SCHOLARONE ${ }^{m}$}

Manuscripts 


\title{
Interannual Variability of the Onset of the South China Sea Summer Monsoon
}

\author{
Ming Luo \\ Department of Geography and Resource Management, The Chinese University of Hong Kong, Shatin, Hong \\ Kong, China. \\ Institute of Environment, Energy and Sustainability, The Chinese University of Hong Kong, Shatin, Hong \\ Kong, China. \\ Yee Leung* \\ Department of Geography and Resource Management, The Chinese University of Hong Kong, Shatin, Hong \\ Kong, China. \\ Institute of Future Cities, The Chinese University of Hong Kong, Shatin, Hong Kong, China. \\ Hans-F. Graf and Michael Herzog \\ Centre for Atmospheric Sciences, University of Cambridge, Cambridge, United Kingdom. \\ Wei Zhang \\ Key Laboratory of Meteorological Disaster of Ministry of Education and Collaborative Innovation Center \\ on Forecast and Evaluation of Meteorological Disasters, Nanjing University of Information Science and \\ Technology, Nanjing, China.
}

\footnotetext{
"Corresponding author address: Department of Geography and Resource Management, Institute of Future Cities, The Chinese University of Hong Kong, Shatin, Hong Kong, China.

E-mail: yeeleung@cuhk.edu.hk
} 


\begin{abstract}
This paper investigates the year-to-year variability of the onset of the South China Sea summer monsoon (SCSSM) and the possible influences exerted by the surface temperature anomalies over land and sea. Early and late monsoon onsets are related to the temperature anomalies in different regions. It is found that an early onset follows negative sea surface temperature (SST) anomalies in the central tropical Pacific (CP) Ocean during the preceding winter and spring, corresponding to a CP La Niña. In contrast, a late onset is preceded by the negative surface air temperature anomalies over land in the central Asian continent.
\end{abstract}

Negative SST anomalies in the central-eastern equatorial Pacific Ocean and the associated warming in the western Pacific induce an anomalously enhanced Walker circulation. This anomalous Walker cell leads to an increase in convection, causing more latent heat release and a subsequent decrease of surface pressure. The anomalous Walker cell and the enhanced latent heat release weaken the Western North Pacific subtropical high and the Philippine Sea anticyclone, favoring a westerly flow from the Indian Ocean, resulting in an early SCSSM onset.

On the other hand, negative land surface temperature anomalies cool the atmosphere over land, and locally modify the Hadley circulation, accompanied by the anomalous divergence in the low-level atmosphere over the western equatorial Pacific. This divergence anomaly reduces the latent heat release and strengthens the anticyclone in the Philippine Sea, thus preventing the westward extension of the westerlies from the Indian Ocean and causing a late SCSSM onset.

Keywords: South China Sea summer monsoon; Onset; Variability; sea surface temperature; land surface temperature; ENSO. 


\section{Introduction}

The South China Sea summer monsoon (SCSSM) is an important component of the Asian summer monsoon system (Tao and Chen, 1987). It indicates the end of the dry season and the beginning of the summer rainy season. The onset of SCSSM is considered as the beginning of the East Asian summer monsoon (Tao and Chen, 1987; Lau and Yang, 1997; Wang et al., 2004a; Li and Zhang, 2009) and it is a key indicator characterizing the abrupt transition from the dry to the rainy season in East Asia (Qian et al., 2002; Wang and Ding, 2006a; Ding, 2007). After its onset, the summer monsoon propagates northward and the Meiyu rain belt establishes itself in South China, the Yangtze and the Huaihe River Basins; the Changma is forming over the Korean Penninsula; and the Baiu is taking place over Japan (Wang and LinHo, 2002; Wang, 2006).

The onset of the SCSSM has been a focus of investigation in recent years (Chen et al., 2000; Ding and Liu, 2001; Ding and Chan, 2005). It has been shown that the SCSSM onset is accompanied by the arrival of an intraseasonal oscillation, which modulates the dry spells and rainy periods during the monsoon season (Wang and $\mathrm{Wu}, 1997$; $\mathrm{Wu}$ and Wang, 2000; Wang et al., 2004; Zhou and Chan, 2005; Bellon et al., 2008). The seasonal cycle and the intraseasonal oscillation make comparable contributions to the SCSSM onset variability (Wu and Wang, 2000). A late (early) onset is accompanied by an active 10-25 (30-60) day intraseasonal variation (Kajikawa and Yasunari, 2005). Wu and Zhang (1998) and Liu et al. (2002) have suggested that the heating of the Tibetan Plateau creates a favorable environment for the onset of the SCSSM.

It has been suggested that tropical sea surface temperature (SST) anomalies and land surface temperature (LST) anomalies (Tanaka, 1997; Zhou and Chan, 2007; Yuan et al., 2008; Liu et al., 2009; Jiang and Li, 2011; Yang et al., 2011) are responsible for the early and late onsets of the SCSSM. Other studies have shown that seasonal changes in SST play an essential role in the climatological SCSSM onset (Wu and Wang, 2000, 2001; Wu, 2002). There is a relatively close relationship between the interannual variability of the SCSSM onset dates and the El Niño/La Niña Southern Oscillation (ENSO) events (Lau and Yang, 1997; Wang et al., 2004; Zhou and Chan, 2007). The late (early) onset of the SCSSM in El Niño (La Niña) years was noticed by Tanaka (1997) and Zhou and Chan (2007). Zhang et al. (2002) regarded that the onset of the summer monsoon over the Indochina Peninsula is closely related to ENSO during the boreal spring. The delayed (advanced) onset of the SCSSM was suggested to be related to the basin-wide warm (cold) events of the Pacific Ocean (Lau and Yang, 1997; Huang et al., 2006). Huang et al. (2006) 
proposed that early (late) SCSSM onset follows the warming (cooling) of the tropical western Pacific. The SCSSM onset date is also affected by the Indian Ocean basin SST anomaly via the modification of the Philippine Sea anticyclone (Yuan et al., 2008). However, these studies only use correlation analysis or composite analysis to classify the ENSO events, possibly insufficient to investigate early or late SCSSM onset nonlinearly affected by other factors.

Previous studies mainly focused on the relationship between the SCSSM onset dates and ENSO events (Lau and Yang, 1997; Wang et al., 2004a; Zhou and Chan, 2007), with the exception of a few that look into the impacts of land surface temperature (LST) anomalies (Liu et al., 2009; Yang et al., 2011). The land-sea thermal contrast, reflected by anomalous land or sea surface temperatures, is an important factor influencing the SCSSM onset since it triggers the Asian monsoon system, especially the South Asian monsoon south of $20^{\circ} \mathrm{N}$ (Wang and Ding, 2006; Ding, 2007; Wu et al., 2012). Because of different rates of temperature change, contributions of sea and land surface temperatures to the land-sea thermal contrast in the transition from spring to summer are different. Nevertheless, very few attempts have been made to investigate the role of LST anomalies preceding the onset of the SCSSM (Liu et al., 2009). For example, Liu et al. (2009) suggested that the SCSSM onset date is affected by different heating rates over land and sea from the preceding winter to the following spring.

A new type of El Niño phenomenon, which is characterized as a warming event in central Pacific (CP) Ocean, has been discovered in recent decades. This is referred to as El Niño Modoki (Ashok et al., 2007; Weng et al., 2007), dateline El Niño (Larkin and Harrison, 2005a,b), CP El Niño or warm Pool El Niño (Kug and Jin, 2009). Yeh et al. (2009) suggested that the occurrence of CP El Niño is related to changes in the background state under global warming, especially changes in the thermocline structure of the equatorial Pacific. Compared with EP El Niño events, CP El Niño events exert different influences on the climate over many parts of the globe (Taschetto and England, 2009; Feng and Li, 2011; Zhang et al., 2012; Graf and Zanchettin, 2012).

Several studies have investigated the impact of these two types of El Niño events on Asian monsoon climate (Weng et al., 2007; Feng et al., 2010, 2011; Wang and Wang, 2012). During the developing year of an El Niño event, EP El Niño is accompanied by an increase in precipitation over southern China, while no significant precipitation changes have been detected in southern China during CP El Niño (Zhang et al., 2011). Feng et al. (2010, 2011) showed opposite precipitation changes in southern China and the Philippine Sea between the two El Niño types during the decaying year. However, the process by 
which CP ENSO influences the onset of the SCSSM has yet to be investigated.

Previous studies have concentrated either on the effects of SST or LST anomalies on SCSSM onset dates, focusing on quasi-linear relationships. However, SST and LST anomalies may also affect the onset of the SCSSM via different mechanisms, which cannot be detected when only one of these factors is considered. Therefore, the objective of this paper is (1) to re-examine the impact of SST anomalies in different regions on the SCSSM onset, and (2) to re-investigate the possible impact of LST anomalies on the onset date of the SCSSM.

The paper is organized as follows. Section 2 describes the dataset, the definition of the SCSSM onset and its interannual variability. Section 3 examines the relationship between the SCSSM onset and SST/LST anomalies. Section 4 discusses possible mechanisms underlying the year-to-year variability of the SCSSM onset. Conclusion and discussion are made in Sections 5 and 6, respectively.

\section{Datasets and Definition}

\subsection{Datasets}

The primary datasets used in this study are obtained from the National Center for Environmental Prediction / National Center for Atmospheric Research (NCEP/NCAR) Reanalysis Project (Kalnay et al., 1996). The temporal coverage is from 1948 to 2009 with the $2.5^{\circ} \times 2.5^{\circ}$ spatial resolution. The climate variables used in this study include: sea level pressure (SLP), $2 \mathrm{~m}$ air temperature, horizontal wind at $850 \mathrm{hPa}$ and $200 \mathrm{hPa}$, and their derived velocity potential and divergence. In addition, we also use interpolated outgoing long-wave radiation (OLR) data, starting from 1979, provided by NOAA/OAR/ESRL PSD, Boulder, Colorado, USA, through their web site at http://www.esrl.noaa.gov/psd/ (Adler et al., 2003; Liebmann and Smith, 1996). The anomalies of surface air temperature $2 \mathrm{~m}$ over land and ocean from the NCEP/NCAR dataset are obtained by removing the climatological average during the period from 1971 to 2000 .

\subsection{Onset date of the SCSSM}

Many indices have been proposed for the determination of the SCSSM onset (Ding, 2004; Wang et al., 2004a). These indices include precipitation and its proxies, such as outgoing long-wave radiation (OLR), upper-tropospheric brightness temperature, high cloud amount, high reflective cloud (Tanaka, 1992; Lin and Lin, 1997; Yan, 1997; Zhu et al., 2001), surface or low-level winds (Lu and Chan, 1999; Wang et al., 2004a), equivalent 
potential temperature (He et al., 2001), or a combination of convection and low-level winds (Liang et al., 1999; Kueh and Lin, 2001). Given the random noise associated with small-scale precipitation variation and the absence of direct precipitation data over oceans (Wang et al., 2004a), we choose to employ a wind circulation index, namely a pentad (5-day) average SCSSM circulation index rather than a precipitation index to characterize large-scale variation. The SCSSM circulation index, $U_{S C S}$, is defined as the area-averaged zonal wind at $850 \mathrm{hPa}$ over the SCS region $(5 \mathrm{~N}-15 \mathrm{~N}, 110 \mathrm{E}-120 \mathrm{E})$. The SCSSM onset date is defined as the first pentad after mid-April $\left(22^{\text {nd }}\right.$ pentad $)$ that satisfies the following criteria (Wang et al., 2004a): (a) $U_{S C S}$ is positive in the onset pentad; (b) $U_{S C S}$ remains positive in at least three pentads and the accumulative 4-pentad mean of $U_{S C S}$ is greater than $1 \mathrm{~ms}^{-1}$ in the subsequent four pentads (including the onset pentad). Based on NCEP/NCAR Reanalysis dataset, the onset date for each year from 1949 to 2009 is calculated and shown in Figure 1. The climatological mean onset date is in mid-May $\left(28.4^{\text {th }}\right.$ pentad). We have also calculated the monsoon onset date based on the ERA-40 reanalysis dataset during the period from 1958 to 2002 (Not shown in here because of the high similarity to that of the NCEP/NCAR results). The two series are almost identical to each other, with a 0.986 correlation significant at the $99 \%$ confidence level.

Subject to the influences of several factors (e.g., tropical SST, LST over Asia, and the heat source condition over the Tibet Plateau), the SCSSM onset shows interannual variability (see Figure 1). The earliest monsoon onset date is in late April $\left(22^{\text {nd }}\right.$ pentad in 2009), while the latest onset date is in late June ( $34^{\text {th }}$ pentad in 1968), giving an almost two months difference in time. To investigate the forcing and mechanisms underlying this year-to-year variability, we focus on the differences between two categories: early onset year (EOY) and late onset year (LOY). EOY and LOY are defined as the year in which the SCSSM onset date is outside the range of \pm 1 standard deviation from the mean. Thus, 15 EOY years, including 1948 1950, 1951, 1953, 1966, 1971, 1972, 1976, 1994, 1996, 1999, 2000, 2001, 2008, 2009, and 14 LOY years, including 1954, 1956, 1957, 1968, 1970, 1973, 1975, 1981, $19821983,1987,1991,1993,2006$, are selected to study the impacts of SST and LST. The remaining years are noted as normal onset years (NOY).

Figure 2 depicts the 2-dimensional evolution of the SCSSM onset process in EOY and LOY, characterized by the composite sequence of pentad OLR and $850 \mathrm{hPa}$ wind from 2 pentads prior to the onset ( -2 pentads) to 1 pentads after the onset $(+1$ pentads). It can be observed that the onset process in EOY is similar to that in LOY. About 2 pentads prior to the onset (-2 pentads), convection dominates the eastern Indian Ocean and most parts of the Indochina Peninsula, and westerly wind prevails over these regions and the Indian 
subcontinent. The westerlies extend eastward and prevail over the Indian subcontinent about 1 pentad before the SCSSM onset ( -1 pentad), and continue to extend eastward to the SCS region followed by the onset of the SCSSM (0 pentad). After the onset $(+1$ pentad), strong convection activity occurs later in the SCS and strong westerly winds keep extending eastward and enter the Philippine Sea. We can also observe that there several differences in the onset processes in EOY and LOY. For instance, convection activities during the eastward extension of the prevailing westerly winds in LOY are stronger than those in EOY. In addition, northern Indian Ocean is covered by stronger prevailing westerly winds in LOY than EOY. These differences should be due to their onset dates. In the following sections, plausible reasons for early and late monsoon onsets and their underlying mechanisms are investigated.

\section{Relationships with surface temperature anomalies}

Firstly, we compare correlations between the SCSSM onset date (MOD) and surface temperature anomalies in different regions. Correlation coefficients of MOD with different SST indices, including Niño 1+2, Niño 3, Niño 3.4, Niño 4, El Niño Modoki index (EMI, proposed by Ashok et al. (2007) to monitor the CP ENSO event) from the preceding January to the following September are shown in Figure 3. SST indices in the preceding winter (during the mature phase of ENSO event) have significant positive correlation with the following SCSSM onset (during the decaying phases of an ENSO event). Among different SST indices, EMI has the highest correlation with MOD, indicating that the zonal SST gradient (or CP ENSO event) exerts a large influence on the SCSSM onset date. These findings imply that the preceding winter surface temperature anomalies are responsible for modulating the SCSSM onset.

To find out more details about the surface temperature patterns associated with SCSSM onset, we examine surface $2 \mathrm{~m}$ air temperature anomaly patterns from the preceding February to May of EOY and LOY. Results are depicted in Figure 4. In EOY, significant negative SST anomaly is found in central Pacific in the preceding February. At the same time, this negative anomaly extends into the eastern Pacific, and positive SST anomalies appear in WNP, particularly in the Philippine Sea and along the southeast coast of China. This is a CP La Niña pattern. The CP La Niña pattern persists until early summer (May). The evolution of tropical SST anomalies in EOY suggests that the preceding winter CP La Niña event is an essential factor leading to an early onset year.

In LOY, however, the opposite SST anomalies pattern is absent, suggesting that a late 
SCSSM onset cannot be explained by the preceding SST anomalies in the tropical Pacific. Nevertheless, the LST anomalies over the Asian continent regulate the late onset of the SCSSM. As shown in Figure 4, a slight but statistically significant cooling over parts of the Asian continent is noticeable in the preceding March of LOY. These negative LST anomalies are strengthened later in April and May, where significant negative LST anomalies dominate many parts of the central-eastern Asian continent. These patterns suggest that the preceding negative LST anomalies over the Asian continent may contribute to the late SCSSM onset.

The above analyses imply that SST and LST anomalies are responsible for the early and late monsoon onsets, respectively. To substantiate this implication, we employ a scatter plot to compare the relationship of the monsoon onset date with the preceding winter EMI (characterizing a CP ENSO event) and the preceding late spring (i.e., April-May) LST anomalies averaged over the central-eastern Asian continent (25N-55N, 85E-135E) where the cooling LST anomaly centers consistently from the preceding March to May. The results are shown in Figure 5. We find that most EOY cases have a negative EMI in the preceding winter; whereas, the LOY cases happen more frequently during the negative LST anomalies. Moreover, the time-lag correlation between LST anomalies and the SCSSM onset dates (see Figure 3) indicate that LST anomaly in the preceding late spring and early summer has the strongest correlation with the following SCSSM onset, suggesting that LST might be a factor contributing to the early or late SCSSM onset. These results further indicate that the EOY and LOY are preferentially modulated by SST and LST anomalies, respectively. It is possible that these modulations are due to different mechanisms further discussed below.

\section{Underlying mechanisms}

We further elucidate possible processes underlying the onset dates of the SCSSM by using composite analysis to investigate the meteorological conditions preceding early and late SCSSM onset. They include sea level pressure (SLP), wind, and large-scale circulation at low- and high-level atmosphere.

\subsection{SLP and winds}

Composite anomalies of SLP and 850hPa wind in EOY and LOY and their differences are shown in Figure 6 and Figure 7. As shown in Figure 6, low pressure anomalies over the western equatorial Pacific and Philippine Sea region persist until the SCSSM onset in 
EOY. This is consistent with the anomalous cyclone at the low-level (i.e., (850 hPa) atmosphere over the region of the WNP anticyclone before the SCSSM onset (see the left panel of Figure 7). This weakening of the WNP anticyclone (shown as cyclone) favors a stronger westerly flow extending from the Indian Ocean, already transporting water vapor into the Philippine Sea in April supporting an early monsoon onset. As depicted in Figure 7, anomalous westerlies also appear in the northern tropical Indian Ocean in EOY during April and May, as a result of the cold SST anomalies in the central-eastern tropical Pacific (i.e., a CP La Niña event).

By contrast, in LOY (right panel of Figure 6), higher pressure is observed over the SCS and WNP region in April, May, and June. This strengthened high pressure leads to an anticyclonic anomaly in the WNP region (see Figure 7). An intensified WNP anticyclone will prevent the Indian Ocean westerlies from extending eastward into the SCS region, thereby causing a late SCSSM onset. It should be noted that, the high pressure anomaly in LOY is much weaker during the winter (e.g. in January through March, figures are not shown) than during the late spring and early summer (i.e., April, May, and June). LOY do not show SLP and SST anomalies in the equatorial Pacific in the preceding winter. This supports that late SCSSM onset is influenced by mechanisms other than SST anomalies in the preceding winter.

\subsection{Large-scale circulations}

As suggested above, an anomalous low-level cyclone accompanied by the low pressure over the Philippine Sea can be observed in EOY. These precursory signals can be connected to the preceding SST anomalies in the central-eastern equatorial Pacific Ocean, possibly by the modification of the Walker circulation. However, LOY follows a strengthened WNP anticyclone and an anomalous high pressure, which are suggested to be related to the preceding SST anomalies. Instead, anticyclone and high pressure anomalies in LOY are associated with the preceding spring LST anomalies over the central-eastern Asian continent, possibly by the modification of the local Hadley circulation. To validate the assumptions, we examine the composite anomalies of the zonal-vertical circulation (Figure 8) and the velocity potential and divergent winds (Figure 8. Composite anomalies of the zonal-vertical circulation of the equatorial region $(0-10 \mathrm{~N})$ prior to the SCSSM onset in EOY (left panel) and LOY (right panel). The vertical component of the vectors is the 
pressure vertical velocity (unit: $P a s-1$, scaled by -100), and the horizontal component is the zonal component of the wind. Shading indicates significance at the $95 \%$ confidence level for vertical velocity.

Figure 9).

Figure 8 shows the composite anomalies of the zonal-vertical circulation of the equatorial region $(0-10 \mathrm{~N})$ prior to the SCSSM onset. In EOY (left panel of Figure 8), a stronger upward branch of the Walker cell is observed over the western equatorial Pacific (between 120E and 140E), Meanwhile, an enhanced anomalous downward branch between $90 \mathrm{E}$ and $110 \mathrm{E}$ is also observed. It can also be observed in Figure 8. Composite anomalies of the zonal-vertical circulation of the equatorial region (0-10N) prior to the SCSSM onset in EOY (left panel) and LOY (right panel). The vertical component of the vectors is the pressure vertical velocity (unit: $P a s-1$, scaled by -100), and the horizontal component is the zonal component of the wind. Shading indicates significance at the $95 \%$ confidence level for vertical velocity.

Figure 9 (left panel), which show the velocity potential and divergent wind at the surface and $100 \mathrm{hPa}$ levels prior to the SCSSM onset, that one convergence center in the lower (i.e., surface) atmosphere appears over the SCS and Philippine Sea and two divergence centers appear over the eastern tropical Indian Ocean and central-eastern tropical Pacific in EOY. These circulation patterns agree with the anomalously strengthened Walker cell (see Figure 8) induced by the La Niña event. The rising branch of the Walker cell leads to divergence aloft. In the lower (i.e., surface) atmosphere, anomalous Walker cell induced convergence over the western equatorial Pacific and divergence over the central Pacific favor eastward extension of the westerlies from the Indian Ocean to the SCS region, leading subsequently to an earlier SCSSM onset.

Compared with EOY, changes of the Walker circulation in LOY are less significant (see Figure 8), suggesting that changes of the Walker circulation forced by ENSO exert less impact on LOY than on EOY, with no significant SST anomalies appearing in the preceding winter or spring of LOY. As shown in the right panels of Figures 8 and 9, in May of LOY, a divergence center over the central Asian continent, a convergence center over South Asia, and a divergence over the Philippine Sea can be observed in the low-level atmosphere. These three anomalies couple with each other, resulting in anomalous local Hadley cell that connects LST anomalies over the central Asian continent to South Asia, and to the WNP regions. The low-level convergence over the central Asian continent is 
consistent with the cold air temperature anomalies over there. Anomalous convergence in the upper-level (i.e., $100 \mathrm{hPa}$ ) atmosphere over the Philippine Sea in LOY is related to the upper-level Hadley cell anomalies. Corresponding to the situation in the upper-level atmosphere, low-level (i.e., surface) divergence appears over the western equatorial Pacific. This is accompanied by the anomalously high pressure and enhanced WNP anticyclone (see Figure 6 and Figure 7), which can also be strengthened by the latent heat release anomaly induced by negative precipitation anomalies (figures are not shown) in this region. Based on the above analysis, we can depict the mechanisms underlying the impacts of LST anomalies on late monsoon onsets. The LST anomalies in the preceding late spring over the Asian continent lead to the cooling in the atmosphere and such changes propagates to the Philippine Sea region to strengthen the WNP anticyclone and subtropical high by enhancing the connection between the Asia and WNP via the modification of the local Hadley cell. The strengthened WNP anticyclone prevents the westerlies from the Indian Ocean from to extend eastward to the SCS and WNP region, leading subsequently to a late SCSSM onset.

\section{Conclusion}

SCSSM onset is a key indicator characterizing the abrupt transition from dry to rainy season in East Asia (Chen et al., 2000; Ding and Liu, 2001; Ding and Chan, 2005). For agricultural management and climate prediction, it is important to identify the reasons and underlying mechanisms for the onset of the SCSSM. In the present study, we have investigated the spatial and temporal characteristics of land and sea surface temperature anomalies, atmospheric circulation and convective activity associated with the interannual variability of the SCSSM onset. To identify the precursor signals and the underlying processes influencing and determining such interannual variability, a composite study has been conducted on the early onset years (EOY) and late onset years (LOY). Analysis results show that CP ENSO plays a more important role in modulating monsoon onset than EP ENSO, given that EOY are preceded by negative SST anomalies centering in the central tropical Pacific. The SCSSM tends to have an earlier onset during years after a CP La Niña event. However, such a clear relationship does not exist for the late onset, suggesting that LOY is caused by mechanisms other than ENSO.

The composite analysis shows that the SCSSM onset is affected by both SST and LST anomalies during the preceding winter and spring. An early SCSSM onset is often preceded by cold SST anomalies in the central-eastern equatorial Pacific (corresponding 
more likely to a CP La Niña than to an EP La Niña event) in winter. A late SCSSM onset is more often dominated by cold LST anomalies in the preceding late spring just before its onset. Both SST and LST anomalies exert impact on the Philippine Sea anticyclone, which will favor or prevent the western extension of the westerlies into the SCS region, so as to advance or delay the onset date of the SCSSM.

More specifically, in EOY, negative SST anomalies in the central-eastern Pacific (i.e., CP La Niña event) increase the zonal temperature gradient and thus enhance the upward branch of the Walker cell over the western Pacific. The related increase in convective activity leads to an increase in precipitation in this region. The increase in precipitation causes more latent heat release, leading to a depression of the surface pressure. The enhanced Walker cell and latent heat release weaken the anticyclone over the Philippine Sea region (shown as anomalous cyclone and low pressure in the lower-level atmosphere). The induced lower pressure over the SCS and Philippine Sea region favors the inflow of the westerlies from the Indian Ocean and Bay of Bengal, subsequently leading to an early SCSSM onset.

In contrast to EOY, LOY are regulated more by temperature anomalies over land and the induced thermal land-sea contrast. Negative LST anomalies cool the atmosphere over land, change the land-sea thermal contrast, modify the local Hadley cell and change the lower- and upper- level atmospheric circulations that connect the cool LST anomalies in the central Asian continent to South Asia, and to the SCS and WNP. Changes of the local Hadley cell and the connection between the central Asian continent and WNP region, together strengthen the surface pressure and anticyclone over the Philippine Sea region. The strengthened anticyclone with higher pressure over the SCS and Philippine Sea region will prevent westerlies from the Indian Ocean to extend eastward to the SCS and WNP region, leading to a late SCSSM onset.

\section{Discussion}

Our analysis results are partially consistent with those of the previous studies (e.g. Zhou and Chan, 2007), providing further evidence for the role of ENSO in affecting the onset of the SCSSM. However, we have found that an early onset is regulated by the preceding negative SST anomalies centering in the central equatorial Pacific, rather in the eastern equatorial Pacific, indicating that CP La Niña plays a more important role in affecting the SCSSM onset. Besides, we have also found that a late onset is influenced more by LST anomalies. The asymmetric effects of SST/LST on early/late onsets may be 
due to the difference in the duration of La Niña and El Niño (Ohba et al., 2010; Okumura and Deser, 2010). Most El Niño events rapidly terminate after their maturing towards the end of the calendar year; whereas, many La Niña events persist into the following year for a longer duration (Ohba et al., 2010; Okumura and Deser, 2010; Okumura et al., 2011). Therefore, La Niña events may exert more influences on the early summer season that follows and exert more impact on the SCSSM onset; whereas, El Niños persist for a shorter duration and exert less influence on monsoon onset. This corresponds to the persistence of the SST anomalies in EOY from the preceding winter to early summer. On the other hand, the SST anomalies in LOY do not show significant El Niño pattern either in the preceding winter or spring.

Beside the contribution of negative SST anomalies in the central-eastern Pacific to the early SCSSM onset, we have also revealed that the preceding negative LST anomalies over the Asian continent contribute to the late SCSSM onset. Land surface is a complex system that interacts with various factors through possibly different processes and mechanisms. The cooling temperature in LOY is likely to be influenced by the surface energy balance. As shown in Figure 10, significant negative anomalies of upward long-wave radiation flux appeared over the central Asian continent, corresponding to negative LST anomalies in these regions (see Figure 4). This implies that such reduced upward long-wave radiation flux could cool the land surface, leading to the negative LST anomalies. Plausible contributing factors like the variation in the snow cover over the Asian continent including the Tibetan Plateau, land use/land cover changes, and related atmospheric circulations such as North Atlantic Oscillation may also be involved (Wu and Qian, 2003; Zhou et al., 2012; Yu et al., 2014). Further work is needed to understand the causes of land surface temperature.

In addition to land and sea surface temperature, other factors such as intraseasonal oscillation activity (intraseasonal fluctuation of the active/break cycles) (Wang and $\mathrm{Wu}$, 1997; Wu and Wang, 2000; Wang et al., 2004; Zhou and Chan, 2005), tropical cyclones (Kajikawa and Wang, 2011), and variations of atmospheric heat source over the Tibetan Plateau (Wu and Zhang, 1998; Liu et al., 2002) can also affect the onset of the SCSSM through various processes. Available reanalysis data sets and the chosen composite method are not sufficient to disentangle these complex relationships in a statistically significant way. Using general circulation models (GCM) is an alternative way to separate the influence of different factors. Such an approach would also reveal the extent to which a state-of-the-art atmospheric climate model can be used to simulate the observed year-to-year variability in the SCSSM onset. 
Recently, some studies have examined the interdecadal variability in summer monsoon onset dates and noticed a significant advance (i.e., half a month earlier) around the mid-1990s in the Asian summer monsoon onset date (Kajikawa and Wang, 2011; Kajikawa et al., 2012; Yuan and Chen, 2013). Changes in the global SST are suggested to be the main reason (Kajikawa and Wang, 2011; Kajikawa et al., 2012; Yuan and Chen, 2013). However, the underlying process is controversial. For instance, Kajikawa and Wang (2011) suggested that the advanced SCSSM onset is influenced by the enhanced activity of the northwestward moving tropical disturbances and the tropical cyclones, possibly caused by the global SST warming. Yuan and Chen (2013) pointed out that it is due to the earlier retreat of the western Northern Pacific subtropical high, which may be caused by the La Niña-like interdecadal change of the Pacific SST. Some studies have found several other responsible factors, such as land-sea thermal contrast (Kajikawa et al., 2012), and anthropogenic absorbing aerosols (Lee et al., 2013). There may exist other factors contributing to the interdecadal change in the SCSSM onset date, and detailed analysis of the impact of these factors on the monsoon onset is also of great research interest. The performance of the state-of-the-art GCM models in simulating this interdecadal change should be evaluated in further studies.

\section{Acknowledgments}

This research was jointly supported by the Geographical Modeling and Geocomputation Program under the Focused Investment Scheme of The Chinese University of Hong Kong, the National Basic Research Program (973 Program) of China (No. 2012CB955800), and the National Natural Science Foundation of China (No. 41401052).

\section{References}

Adler, R. F., G. J. Huffman, A. Chang, R. Ferraro, P. Xie, J. Janowiak, B. Rudolf, U. Schneider, S. Curtis, D. Bolvin, A. Gruber, J. Susskind, P. Arkin, and E. Nelkin, 2003. The version-2 global precipitation climatology project (GPCP) monthly precipitation analysis (1979-present). Journal of Hydrometeorology, 4: 1147-1167.

Ashok, K., S. K. Behera, S. A. Rao, H. Y. Weng, and T. Yamagata, 2007. El Niño Modoki and its possible teleconnection. Journal of Geophysical Research-Oceans, 112: C11007.

Bellon, G., A. H. Sobel, and J. Vialard, 2008. Ocean-atmosphere coupling in the monsoon 
intraseasonal oscillation: A simple model study. Journal of Climate, 21: 5254-5270.

Chen, T. C., M. C. Yen, and S. P. Weng, 2000. Interaction between the summer monsoons in East Asia and the South China Sea: Intraseasonal monsoon modes. Journal of the Atmospheric Sciences, 57: 1373-1392.

Ding, Y. H., 2004. Seasonal march of the East-Asian summer monsoon. East Asian Monsoon, C. P. Chang, Ed., World Scientific, Singapore, 3-53.

Ding, Y. H., 2007. The variability of the Asian summer monsoon. Journal of the Meteorological Society of Japan, 85B: 21-54.

Ding, Y. H. and J. C. L. Chan, 2005. The East Asian summer monsoon: An overview. Meteorology and Atmospheric Physics, 89: 117-142.

Ding, Y. H. and Y. J. Liu, 2001. Onset and the evolution of the summer monsoon over the South China Sea during SCSMEX field experiment in 1998. Journal of the Meteorological Society of Japan, 79: 255-276.

Fan, Y. and H. van den Dool, 2008. A global monthly land surface air temperature analysis for 1948-present. Journal of Geophysical Research-Atmospheres, 113: D01103.

Feng, J., W. Chen, C. Y. Tam, and W. Zhou, 2011. Different impacts of El Niño and El Niño Modoki on China rainfall in the decaying phases. International Journal of Climatology, 31: 2081-2101.

Feng, J. and J. P. Li, 2011. Influence of El Niño Modoki on spring rainfall over south China. Journal of Geophysical Research-Atmospheres, 116: D13102.

Feng, J., L. Wang, W. Chen, S. K. Fong, and K. C. Leong, 2010. Different impacts of two types of Pacific Ocean warming on Southeast Asian rainfall during boreal winter. Journal of Geophysical Research-Atmospheres, 115: D24122.

Gao, H., J. He, Y. Tan, and J. Liu, 2001. Definition of 40-year onset date of South China Sea summer monsoon. Journal of Nanjing Institute of Meteorology, 24: 379-383.

Graf, H.-F. and D. Zanchettin, 2012. Central Pacific El Niño, the "subtropical bridge", and Eurasian climates. Journal of Geophysical Research, 117: D01102.

Huang, R., L. Gu, L. Zhou, and S. Wu, 2006. Impact of the thermal state of the tropical western Pacific on onset date and process of the South China Sea summer monsoon. Advances in Atmospheric Sciences, 23: 909-924.

Jiang, X. W. and J. P. Li, 2011. Influence of the annual cycle of sea surface temperature on the monsoon onset. Journal of Geophysical Research, 116: D10105.

Kajikawa, Y. and B. Wang, 2011. Interdecadal change of the South China Sea summer monsoon onset. Journal of Climate, 25: 3207-3218.

Kajikawa, Y. and T. Yasunari, 2005. Interannual variability of the 10-25-and 30-60-day 
variation over the South China Sea during boreal summer. Geophysical Research Letters, 32: L04710.

Kajikawa, Y., T. Yasunari, S. Yoshida, and H. Fujinami, 2012. Advanced Asian summer monsoon onset in recent decades. Geophysical Research Letters, 39, L03803.

Kalnay, E., et al., 1996. The NCEP/NCAR 40-year reanalysis project. Bulletin of the American Meteorological Society, 77: 437-471.

Kueh, M. T. and S. C. Lin, 2001. South China Sea summer monsoon: Onset definition and characteristics. Atmospheric Science, 29: 141-170.

Kug, J. S. and F. F. Jin, 2009. Two types of El Niño events: Cold tongue El Niño and warm pool El Niños. Journal of Climate, 22: 1499-1515.

Larkin, N. K. and D. E. Harrison, 2005a. Global seasonal temperature and precipitation anomalies during El Niño autumn and winter. Geophysical Research Letters, 32: L16705.

Larkin, N. K. and D. E. Harrison, 2005b. On the definition of El Niño and associated seasonal average US weather anomalies. Geophysical Research Letters, 32: L13705.

Lau, K. M. and S. Yang, 1997. Climatology and interannual variability of the Southeast Asian summer monsoon. Advances in Atmospheric Sciences, 14: 141-162.

Lee, S.-Y., H.-J. Shin, and C. Wang, 2013. Nonlinear effects of coexisting surface and atmospheric forcing of anthropogenic absorbing aerosols: Impact on the South Asian monsoon onset. Journal of Climate, 26, 5594-5607.

Li, C., and M. Yanai, 1996. The onset and interannual variability of the Asian summer monsoon in relation to land-sea thermal contrast. Journal of Climate, 9, 358-375.

Li, J. P. and L. Zhang, 2009. Wind onset and withdrawal of Asian summer monsoon and their simulated performance in AMIP models. Climate Dynamics, 32(7-8): 935-968.

Liang, J., S. Wu, and J. You, 1999. The research on variations of onset time of the SCS summer monsoon and its intensity. Journal of Tropical Meteorology, 15: 97105.

Liebmann, B. and C. A. Smith, 1996. Description of a complete (interpolated) outgoing longwave radiation dataset. Bulletin of the American Meteorological Society, 77: 12751277.

Lin, P. H. and H. Lin, 1997. The Asian summer monsoon and Mei-Yu front Part I: Cloud patterns as a monsoon index. Atmospheric Science, 25: 267-287.

Liu, P., Y. F. Qian, and A. N. Huang, 2009. Impacts of land surface and sea surface temperatures on the onset date of the South China Sea summer monsoon. Advances in Atmospheric Sciences, 26: 493-502.

Liu, Y. M., J. C. L. Chan, J. Y. Mao, and G. X. Wu, 2002. The role of Bay of Bengal 
convection in the onset of the 1998 South China Sea summer monsoon. Monthly Weather Review, 130: 2731-2744.

Lu, E. and J. C. L. Chan, 1999. A unified monsoon index for south China. Journal of Climate, 12: 2375-2385.

Okumura, Y. M., and C. Deser, 2010. Asymmetry in the duration of El Niño and La Niña. Journal of Climate, 23, 5826-5843.

Okumura, Y. M., M. Ohba, C. Deser, and H. Ueda, 2011. A proposed mechanism for the asymmetric duration of El Niño and La Niña. Journal of Climate, 24, 3822-3829.

Ohba, M., D. Nohara, and H. Ueda, 2010. Simulation of asymmetric ENSO transition in WCRP CMIP3 multimodel experiments. Journal of Climate, 23, 6051-6067.

Qian, W., H. S. Kang, and D. K. Lee, 2002. Distribution of seasonal rainfall in the East Asian monsoon region. Theoretical and Applied Climatology, 73: 151-168.

Rayner, N. A., D. E. Parker, E. B. Horton, C. K. Folland, L. V. Alexander, D. P. Rowell, E. C. Kent, and A. Kaplan, 2003. Global analyses of sea surface temperature, sea ice, and night marine air temperature since the late nineteenth century. Journal of Geophysical Research-Atmospheres, 108: 4407.

Tanaka, M., 1992. Intraseasonal oscillation and the onset and retreat dates of the summer monsoon over East, Southeast Asia and the western Pacific region using GMS high cloud amount data. Journal of Meteorological Society of Japan, 70: 613-629.

Tanaka, M., 1997. Interannual and interdecadal variations of the western North Pacific monsoon and the East Asian Baiu rainfall and their relationship to ENSO cycles. Journal of the Meteorological Society of Japan, 75: 1109-1123.

Tao, S. Y. and L. X. Chen, 1987. A review of recent research on the East Asian summer monsoon in China. Monsoon Meteorology, C. P. Chang and T. N. Krishnamurti, Eds., Oxford University Press, Oxford.

Taschetto, A. S. and M. H. England, 2009. El Niño Modoki impacts on Australian rainfall. Journal of Climate, 22: 3167-3174.

Wang, B., 2006. The Asian Monsoon. Springer, Chichester.

Wang, B. and Q. H. Ding, 2006. Changes in global monsoon precipitation over the past 56 years. Geophysical Research Letters, 33: L06711.

Wang, B. and LinHo, 2002. Rainy season of the Asian-Pacific summer monsoon. Journal of Climate, 15: 386-398.

Wang, B., LinHo, Y. S. Zhang, and M. M. Lu, 2004. Definition of South China Sea monsoon onset and commencement of the East Asia summer monsoon. Journal of Climate, 17: 699-710. 
Wang, B. and R. G. Wu, 1997. Peculiar temporal structure of the South China Sea summer monsoon. Advances in Atmospheric Sciences, 14: 177-194.

Wang, C. and X. Wang, 2012. El Niño Modoki I and II classifying by different impacts on rainfall in Southern China and typhoon tracks. Journal of Climate, 26: 1322-1338.

Weng, H. Y., K. Ashok, S. K. Behera, S. A. Rao, and T. Yamagata, 2007. Impacts of recent El Niño Modoki on dry/wet conditions in the Pacific rim during boreal summer. Climate Dynamics, 29: 113-129.

Wu, G. X., Y. Liu, B. He, Q. Bao, A. Duan, and F.-F. Jin, 2012. Thermal controls on the Asian Summer monsoon. Scientific Reports, 2: 404.

Wu, G. X. and Y. S. Zhang, 1998. Tibetan Plateau forcing and the timing of the monsoon onset over South Asia and the South China Sea. Monthly Weather Review, 126: 913927.

Wu, R. G. and B. Wang, 2001. Multi-stage onset of the summer monsoon over the western North Pacific. Climate Dynamics, 17: 277-289.

Wu, R. G., 2002. A mid-latitude Asian circulation anomaly pattern in boreal summer and its connection with the Indian and East Asian summer monsoons. International Journal of Climatology, 22: 1879-1895.

Wu, R. G. and B. Wang, 2000. Interannual variability of summer monsoon onset over the western North Pacific and the underlying processes. Journal of Climate, 13: 24832501.

Wu, T.-W., and Z.-A. Qian, 2003. The relation between the Tibetan winter snow and the Asian summer monsoon and rainfall: An observational investigation. Journal of Climate, 16, 2038-2051.

Yan, J., 1997: Observational study on the onset of the South China Sea southwest monsoon. Advances in Atmospheric Sciences, 14: 277-287.

Yang, S., W. Min, R. Q. Yang, W. Higgins, and Z. Renhe, 2011. Impacts of land process on the onset and evolution of Asian summer monsoon in the NCEP climate forecast system. Advances in Atmospheric Sciences, 28: 1301-1317.

Yeh, S. W., J. S. Kug, B. Dewitte, M. H. Kwon, B. P. Kirtman, and F. F. Jin, 2009. El Niño in a changing climate. Nature, 461: 511-U70.

Yu, B., X. L. Wang, X. B. Zhang, J. Cole, and Y. Feng, 2014. Decadal covariability of the northern wintertime land surface temperature and atmospheric circulation. Journal of Climate, 27, 633-651.

Yuan, Y., W. Zhou, J. C. L. Chan, and C. Y. Li, 2008. Impacts of the basin-wide Indian Ocean SSTA on the South China Sea summer monsoon onset. International Journal of 
Climatology, 28: 1579-1587.

Yuan, F., and W. Chen, 2013. Roles of the tropical convective activities over different regions in the earlier onset of the South China Sea summer monsoon after 1993. Theoretical and Applied Climatology, 113, 175-185.

Zhang, W., H.-F. Graf, Y. Leung, and M. Herzog, 2012. Different El Niño types and tropical cyclone landfall in East Asia. Journal of Climate, 25: 6510-6523.

Zhang, W. J., F. F. Jin, J. P. Li, and H. L. Ren, 2011. Contrasting impacts of two-type El Niño over the Western North Pacific during boreal autumn. Journal of the Meteorological Society of Japan, 89: 563-569.

Zhang, Y. S., T. Li, B. Wang, and G. X. Wu, 2002. Onset of the summer monsoon over the Indochina Peninsula: Climatology and interannual variations. Journal of Climate, 15: 3206-3221.

Zhou, L., Y. Tian, S. B. Roy, C. Thorncroft, L. F. Bosart, and Y. Hu, 2012. Impacts of wind farms on land surface temperature. Nature Climate Change, 2, 539-543.

Zhou, W. and J. C. L. Chan, 2005. Intraseasonal oscillations and the South China Sea summer monsoon onset. International Journal of Climatology, 25: 1585-1609.

Zhou, W. and J. C. L. Chan, 2007: ENSO and the South China Sea summer monsoon onset. International Journal of Climatology, 27: 157-167.

Zhu, Y., Y. Li, and W. Qian, 2001. Comparison of the SCS summer monsoon onset, characteristics derived from different datasets. Journal of Tropical Meteorology, 17: 34-44. 


\section{Figures}

Figure 1. Time series of the SCSSM onset date (MOD) from 1948 to 2009. The dashed lines indicate \pm 1 standard deviation from the mean.

Figure 2. Composite pentad OLR (shading, unit: $W \mathrm{~m}^{-2}$ ) and $850 \mathrm{hPa}$ winds (vector, unit: $m \mathrm{~s}^{-1}$ ) showing the monsoon onset evolution in EOY (left panel) and LOY (right panel) from -2 to +1 pentad ( 0 pentad represents the onset pentad). Winds less than $2 \mathrm{~m} \mathrm{~s}^{-1}$ are omitted here.

Figure 3. Correlation coefficients between MOD and different SST indices (i.e., Niño 1+2, Niño 3, Niño 3.4, Niño 4, and EMI) and LST anomalies averaged in 25E-55N, 85E-135E from the preceding January to the following September. Dashed thick (thin) lines indicate that correlation is significant at the $95 \%$ (90\%) confidence level.

Figure 4. Composite anomalies of land and sea surface $2 \mathrm{~m}$ air temperature (unit: ${ }^{\circ} \mathrm{C}$ ) during the previous winter, spring, and summer in EOY (left panel) and LOY (right panel). Solid (dashed) contours indicate positive (negative) anomalies. Dark (light) shading indicates positive (negative) anomalies significant at the 95\% confidence level.

Figure 5. Scatter plot of the preceding winter EMI and May LST in EOY, LOY, and NOY. Solid circles, diamonds, and hollow circles indicate early (EOY), late (LOY), and normal onset years (NOY), respectively.

Figure 6. Composite anomalies of SLP (unit: $h \mathrm{~Pa}$ ) prior to the SCSSM onset in EOY (left panel) and LOY (panel), and their differences. Dark (light) shading indicates positive (negative) anomalies significant at the $95 \%$ confidence level.

Figure 7. Composite anomalies of $850 \mathrm{hPa}$ wind (unit: $\mathrm{m} \mathrm{s}^{-1}$ ) prior to the SCSSM onset in EOY (left panel) and LOY (right panel), and their difference. Shading indicates significance at the $95 \%$ confidence level.

Figure 8. Composite anomalies of the zonal-vertical circulation of the equatorial region $(0-10 \mathrm{~N})$ prior to the SCSSM onset in EOY (left panel) and LOY (right panel). The vertical component of the vectors is the pressure vertical velocity (unit: $P a s^{-1}$, scaled by -100), and the horizontal component is the zonal component of the wind. Shading indicates significance at the $95 \%$ confidence level for vertical velocity.

Figure 9. Composite anomalies of velocity potential (contour, unit: $m \mathrm{~s}^{-1}$, scaled by $10^{6}$ ) 
and divergent wind (vector, unit: $\mathrm{m} \mathrm{s}^{-1}$ ) at surface and 100h hPa levels in (left) April of EOY and (right) May of LOY. Shading indicates significance at the 95\% confidence level for velocity potential or divergent wind.

Figure 10. Composite anomalies of upward long-wave radiation flux (unit: $W m^{-2}$ ) in LOY. Shading indicates significance at the $95 \%$ confidence level. 


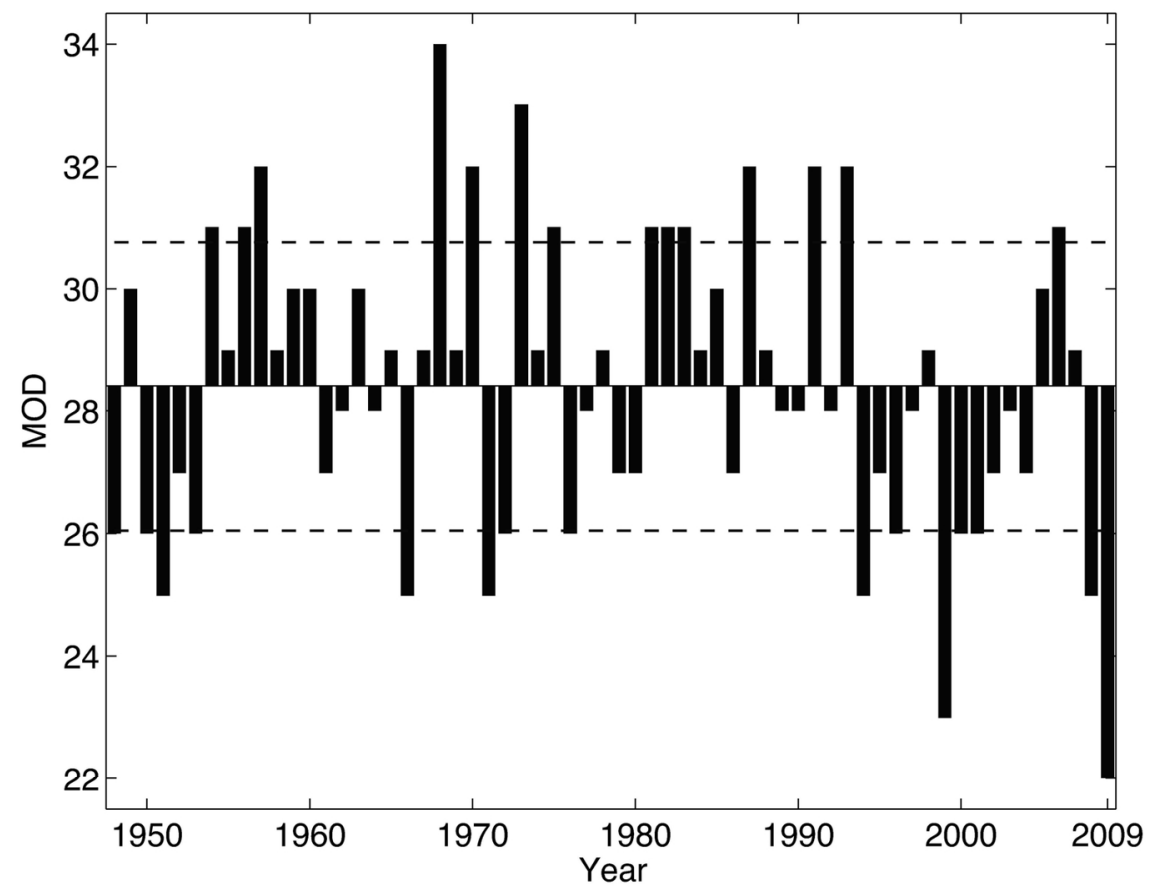

Figure1. Time series of the SCSSM onset date (MOD) from 1948 to 2009. The dashed lines indicate \pm 1 standard deviation from the mean. $148 \times 110 \mathrm{~mm}(300 \times 300 \mathrm{DPI})$ 

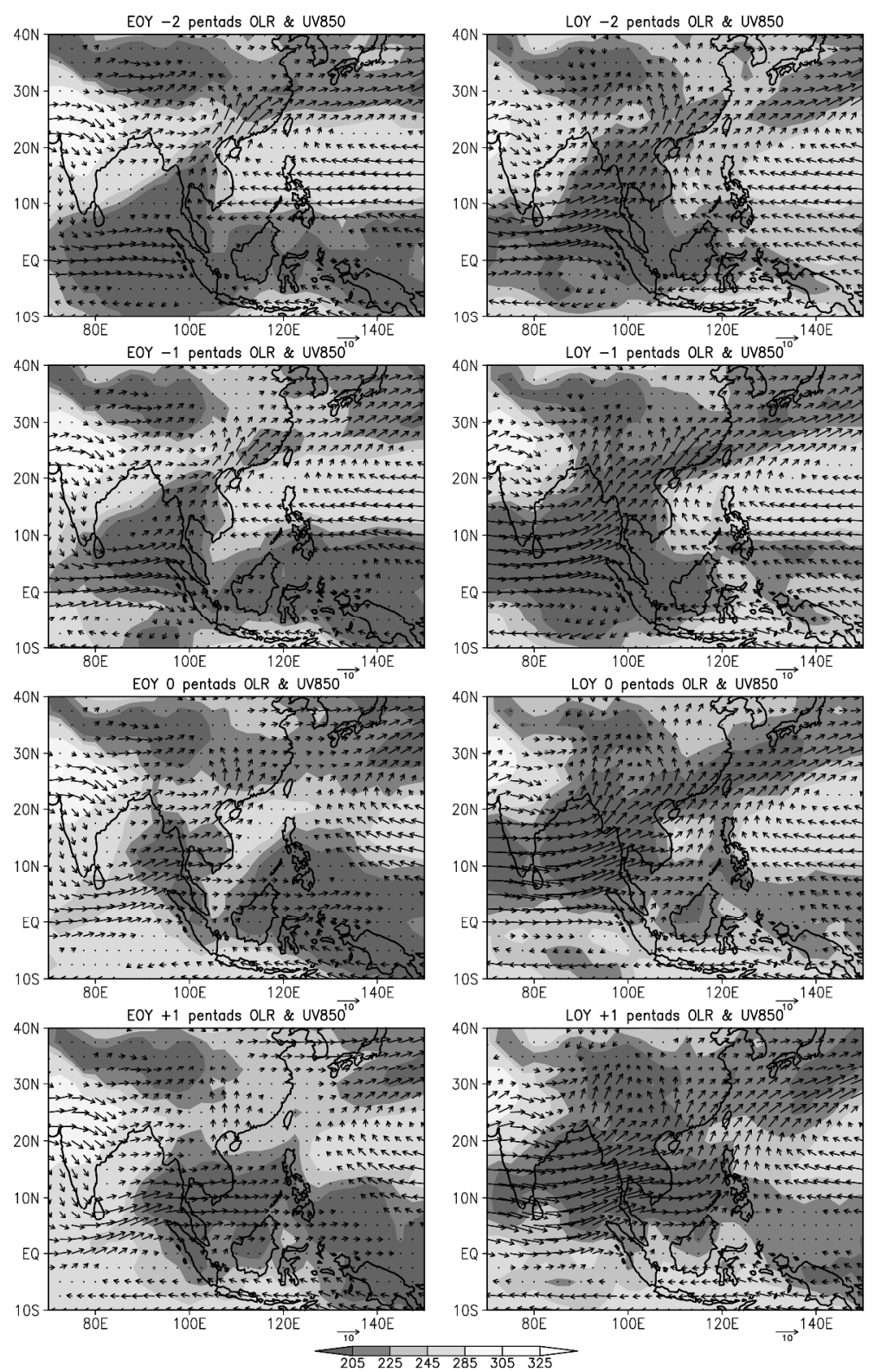

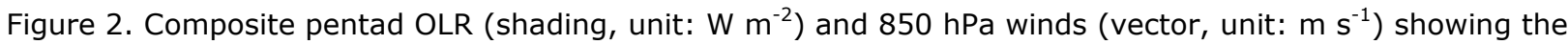
monsoon onset evolution in EOY (left panel) and LOY (right panel) from -2 to +1 pentad ( 0 pentad represents the onset pentad). Winds less than $2 \mathrm{~m} \mathrm{~s}^{-1}$ are omitted here. $504 \times 801 \mathrm{~mm}(300 \times 300$ DPI $)$ 


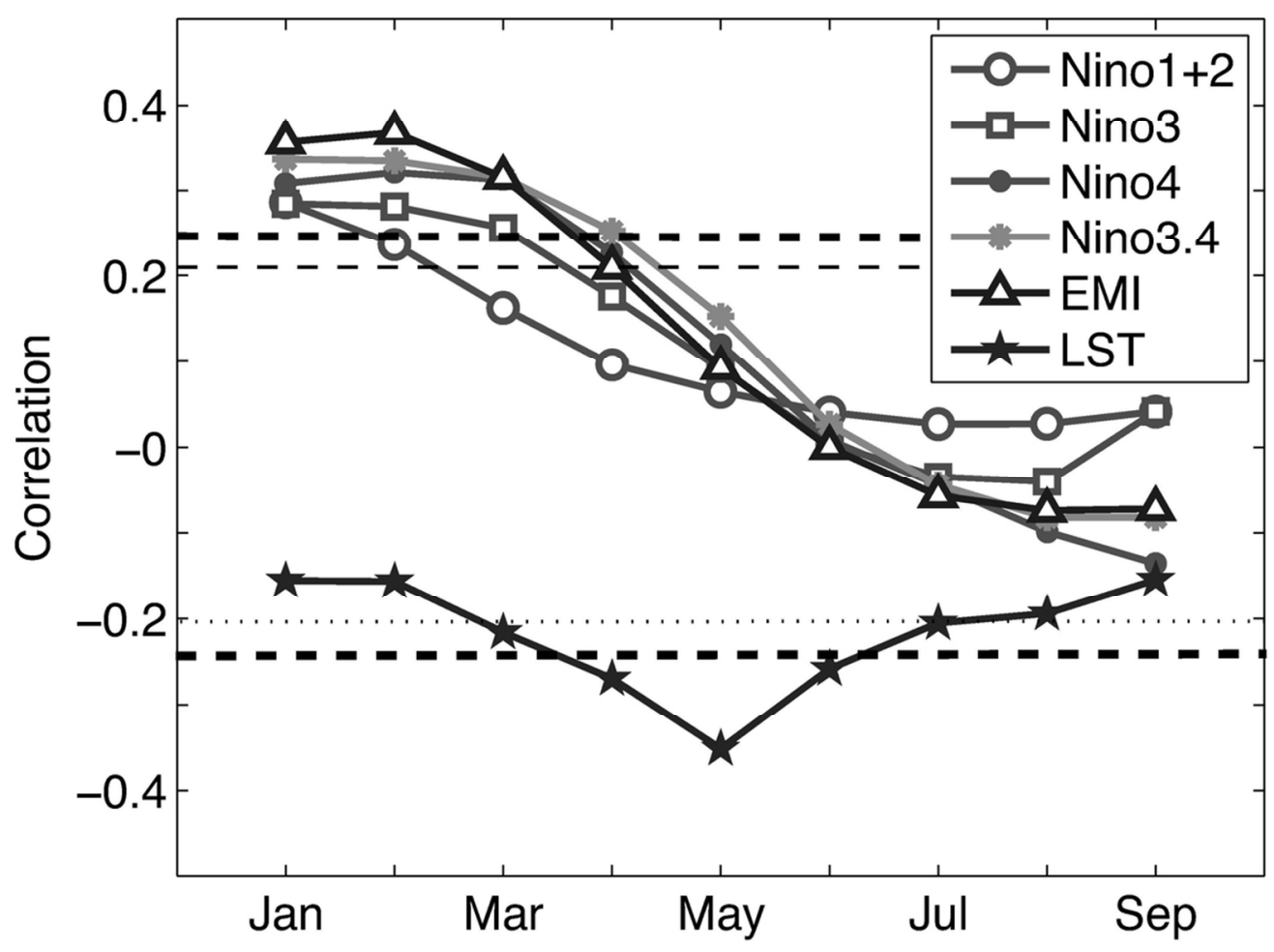

Figure 3. Correlation coefficients between MOD and different SST indices (i.e., Niño 1+2, Niño 3, Niño 3.4, Niño 4, and EMI) and LST anomalies averaged in 25E-55N, 85E-135E from the preceding January to the following September. Dashed thick (thin) lines indicate that correlation is significant at the $95 \%(90 \%)$ confidence level. $100 \times 75 \mathrm{~mm}(300 \times 300 \mathrm{DPI})$ 

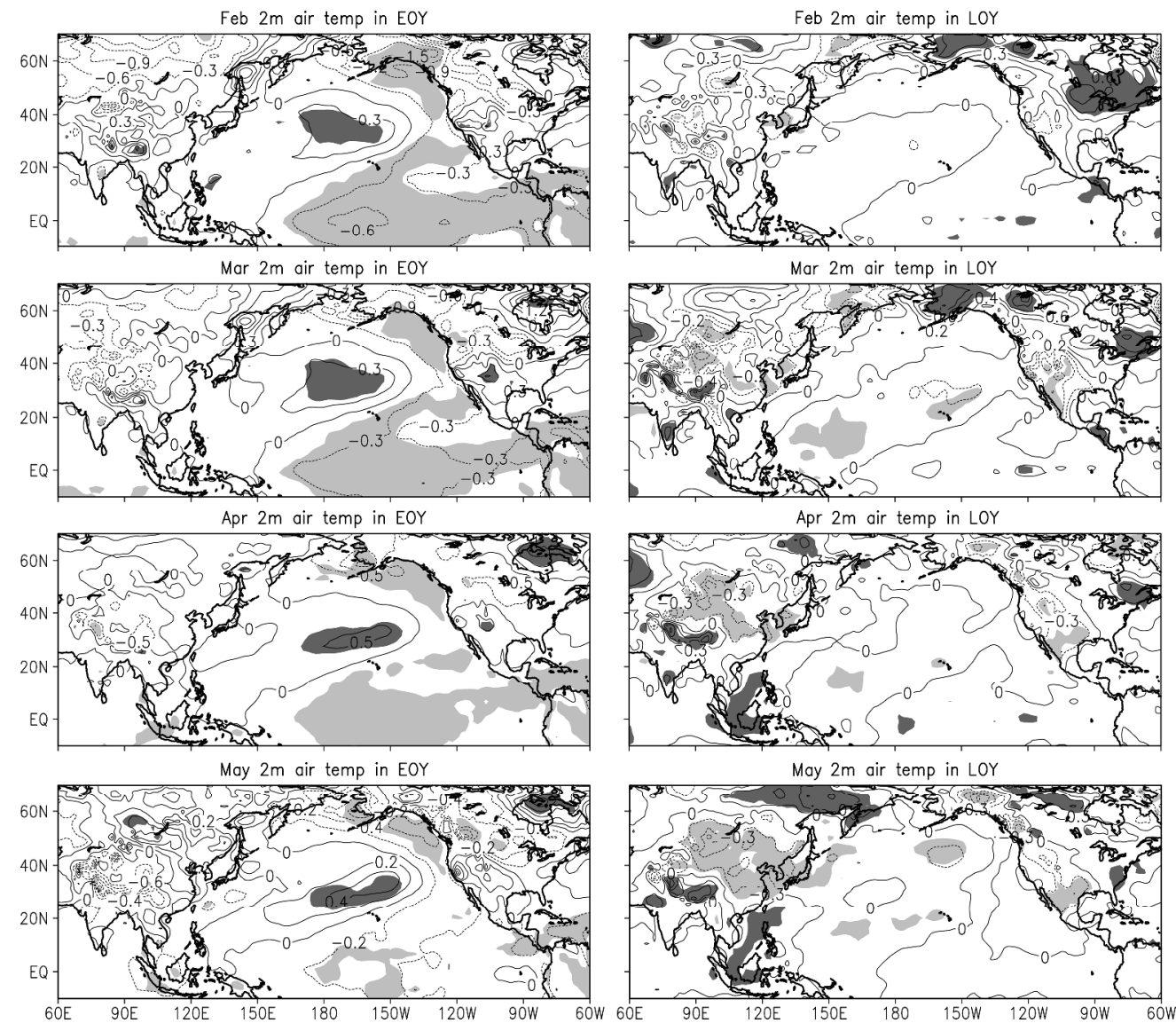

May $2 m$ air temp in LOY

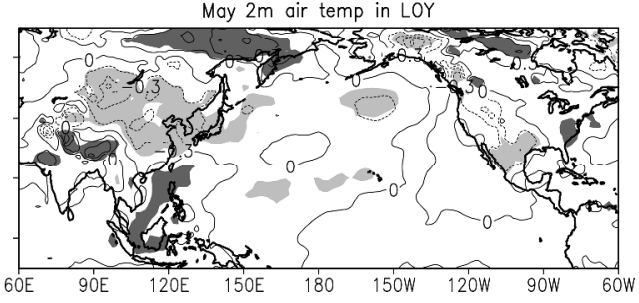

Figure 4. Composite anomalies of land and sea surface $2 \mathrm{~m}$ air temperature (unit: ${ }^{\circ} \mathrm{C}$ ) during the previous winter, spring, and summer in EOY (left panel) and LOY (right panel). Solid (dashed) contours indicate positive (negative) anomalies. Dark (light) shading indicates positive (negative) anomalies significant at the $95 \%$ confidence level. $394 \times 344 \mathrm{~mm}(300 \times 300$ DPI $)$ 


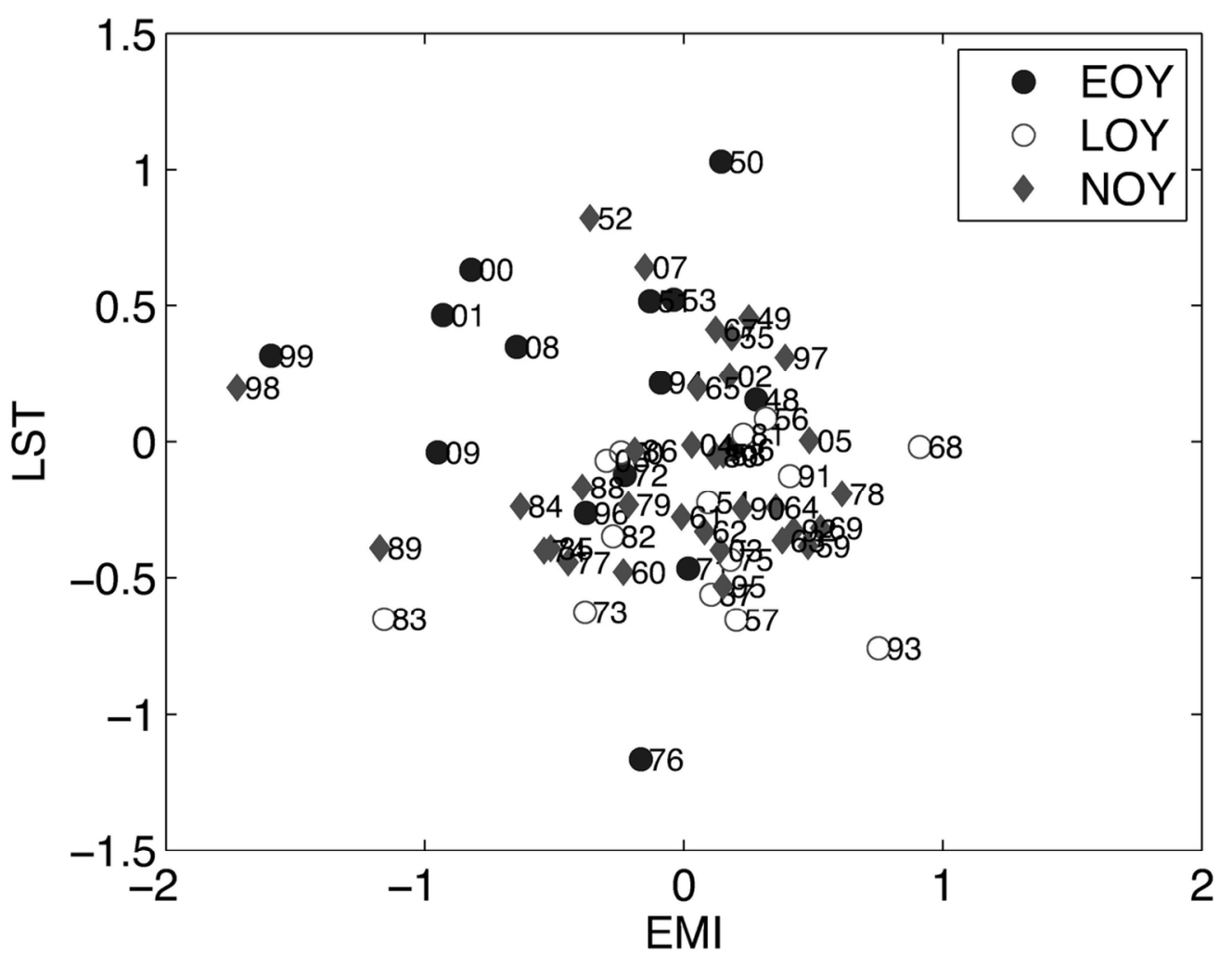

Figure 5. Scatter plot of the preceding winter EMI and May LST in EOY, LOY, and NOY. Solid circles, diamonds, and hollow circles indicate early (EOY), late (LOY), and normal onset years (NOY), respectively. $106 \times 84 \mathrm{~mm}(300 \times 300 \mathrm{DPI})$ 

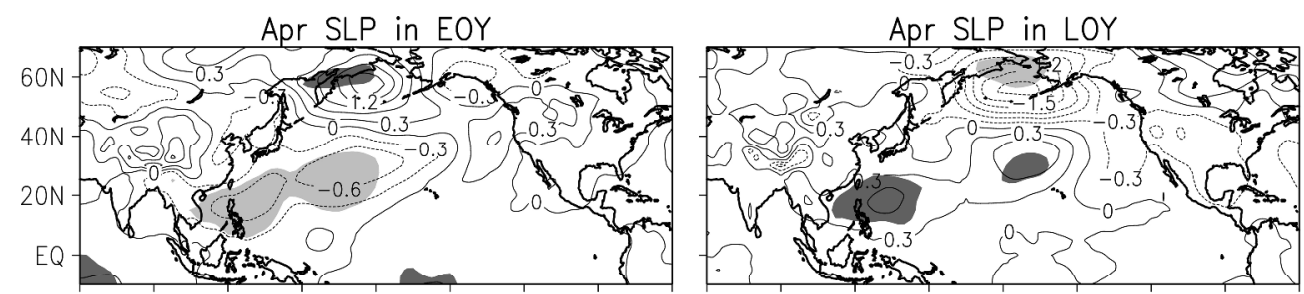

May SLP in EOY
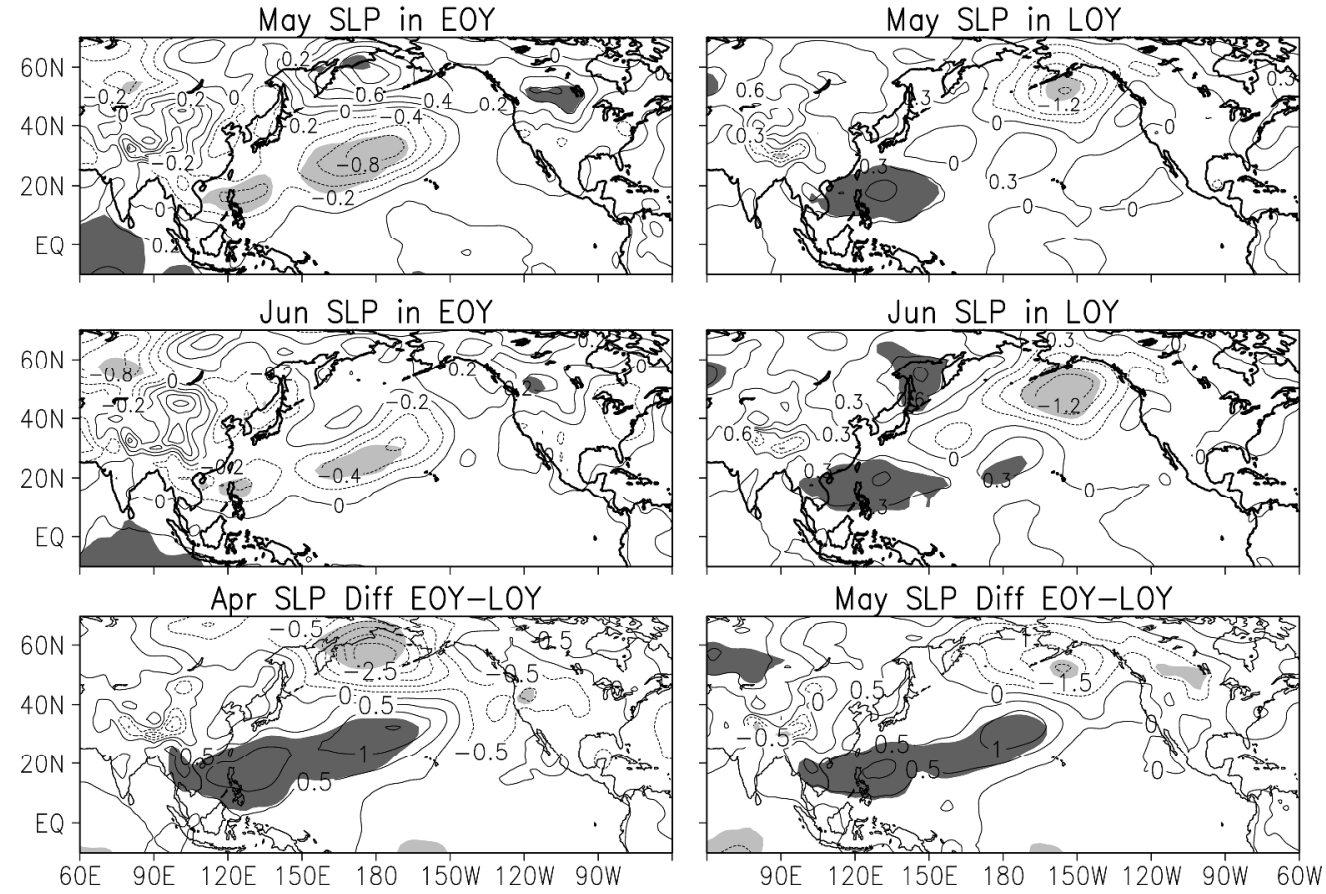

Figure 6. Composite anomalies of SLP (unit: hPa) prior to the SCSSM onset in EOY (left panel) and LOY (panel), and their differences. Dark (light) shading indicates positive (negative) anomalies significant at the $95 \%$ confidence level. $364 \times 325 \mathrm{~mm}(300 \times 300 \mathrm{DPI})$ 

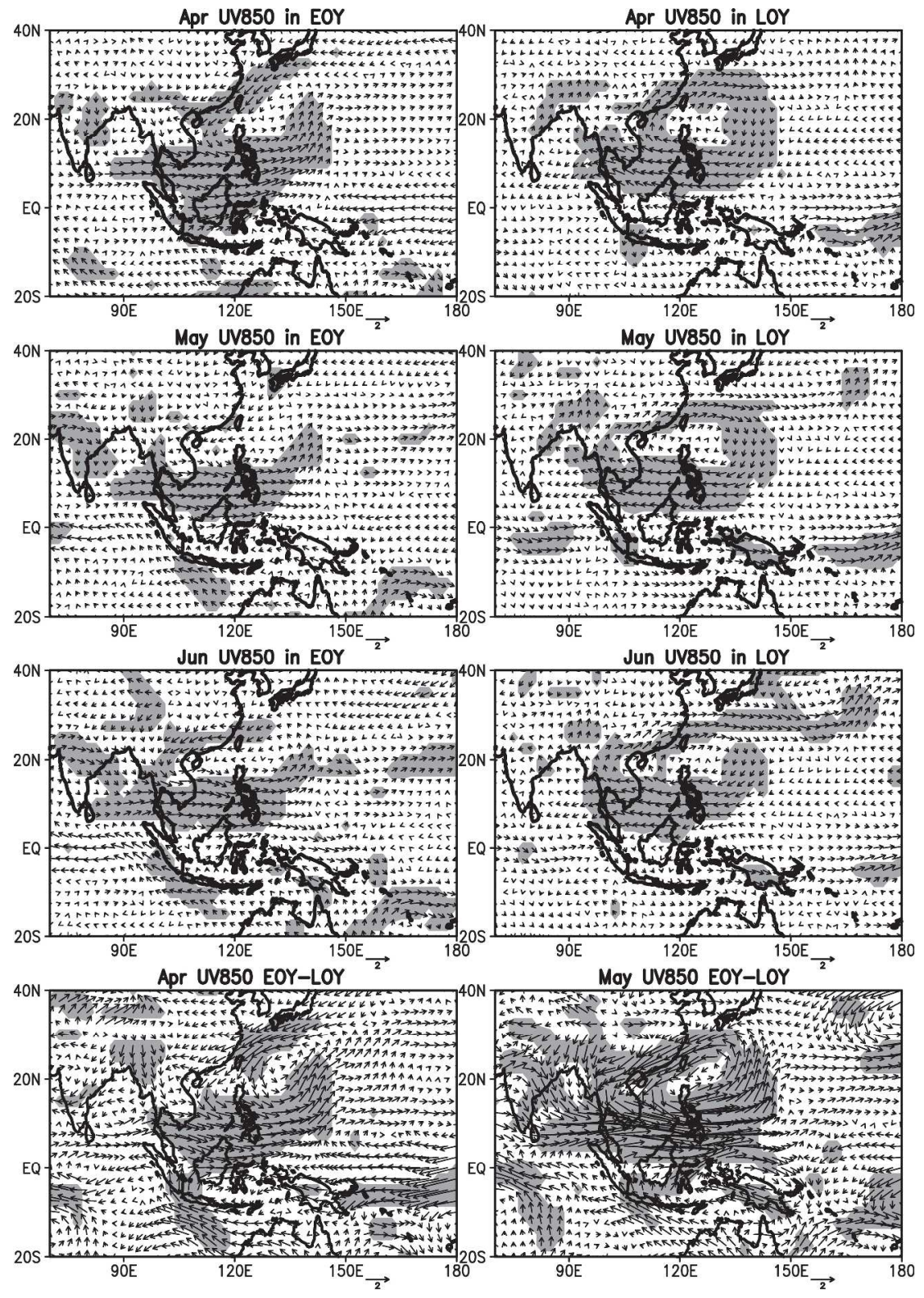

Figure 7. Composite anomalies of $850 \mathrm{hPa}$ wind (unit: $\mathrm{m} \mathrm{s}^{-1}$ ) prior to the SCSSM onset in EOY (left panel) and LOY (right panel), and their difference. Shading indicates significance at the $95 \%$ confidence level. $295 \times 420 \mathrm{~mm}(300 \times 300$ DPI $)$ 

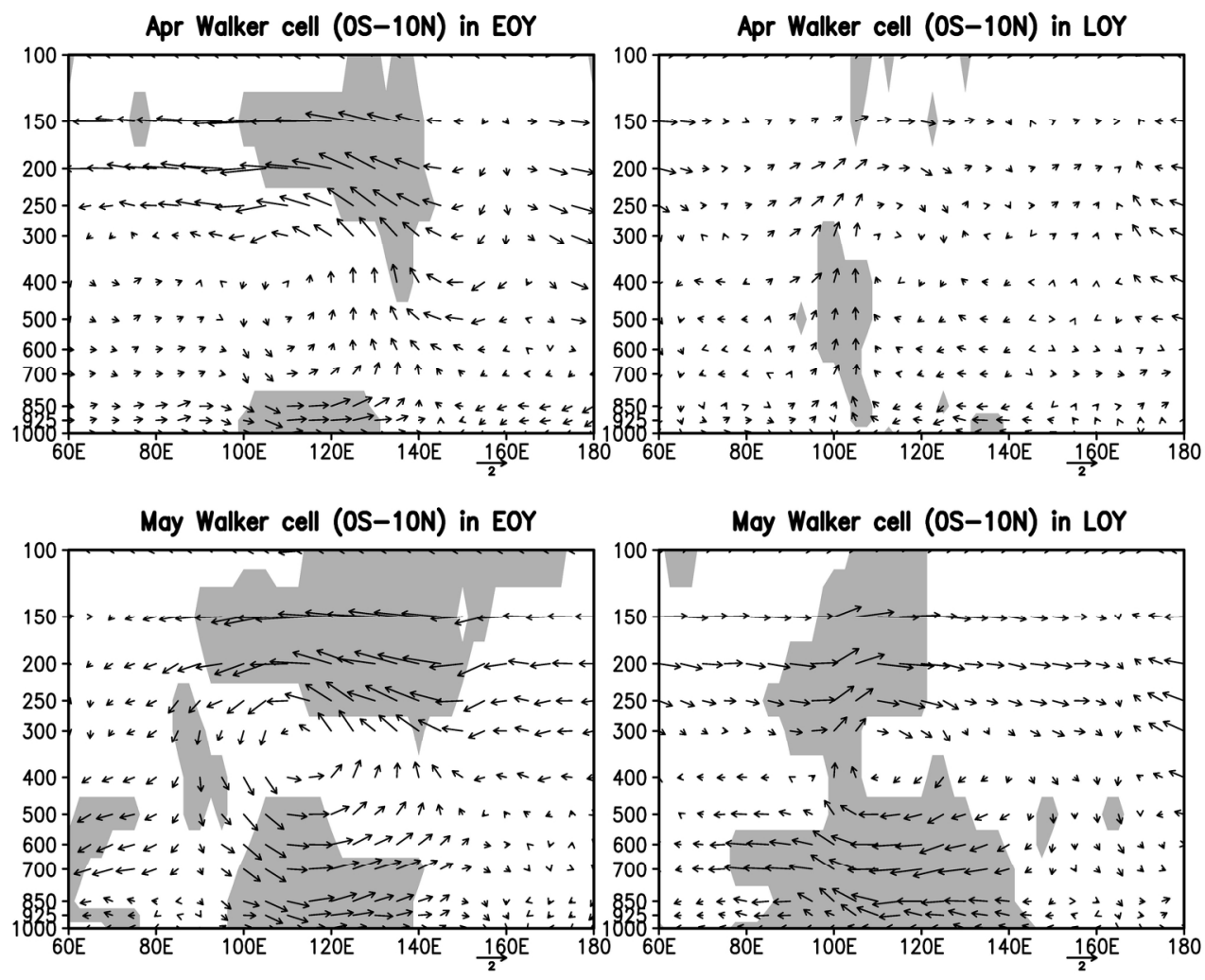

Figure 8. Composite anomalies of the zonal-vertical circulation of the equatorial region $(0-10 \mathrm{~N})$ prior to the SCSSM onset in EOY (left panel) and LOY (right panel). The vertical component of the vectors is the pressure vertical velocity (unit: $\mathrm{Pa} \mathrm{s}^{-1}$, scaled by -100 ), and the horizontal component is the zonal component of the wind. Shading indicates significance at the $95 \%$ confidence level for vertical velocity. $177 \times 142 \mathrm{~mm}(300 \times 300 \mathrm{DPI})$ 

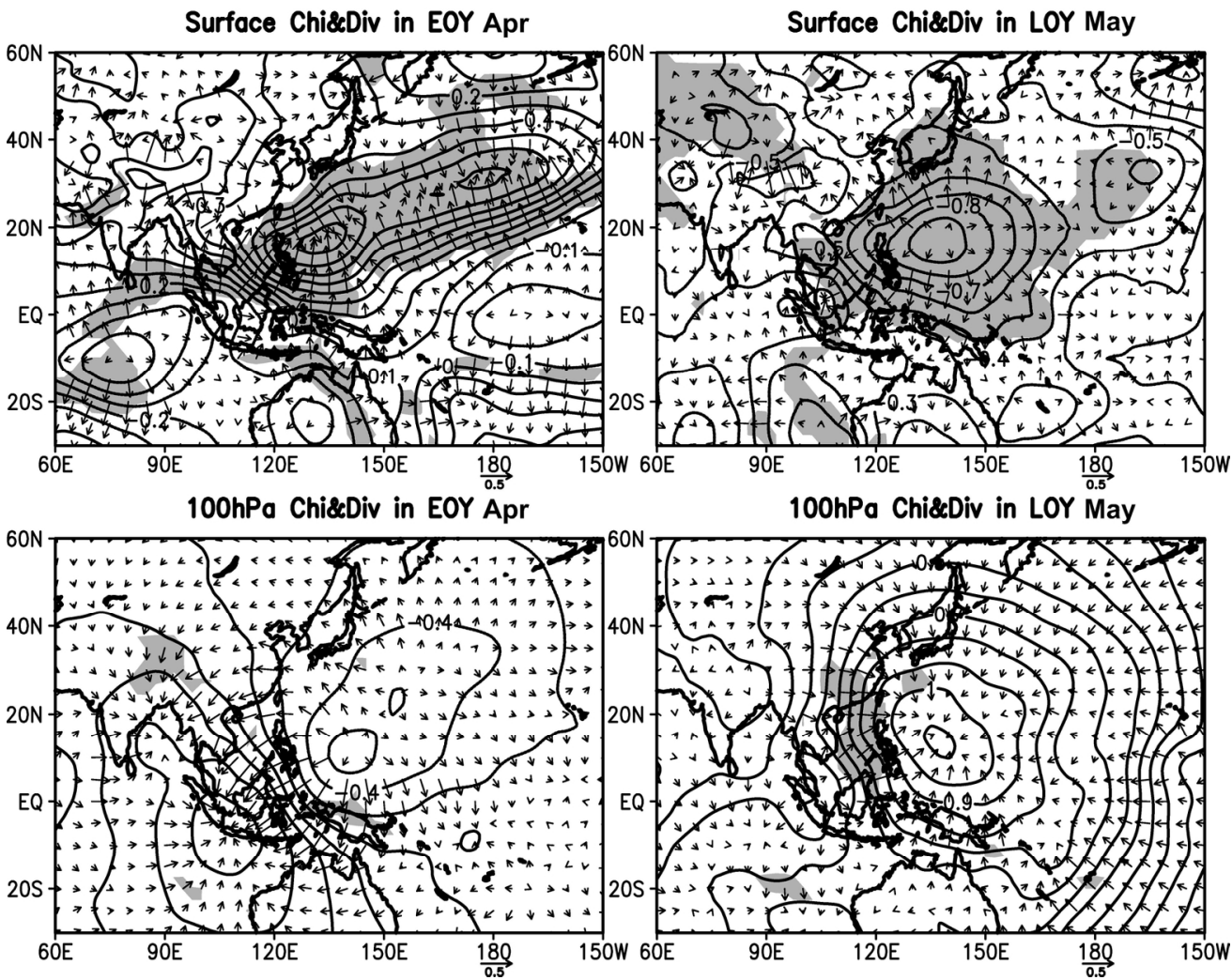

Figure 9. Composite anomalies of velocity potential (contour, unit: $\mathrm{m} \mathrm{s}^{-1}$, scaled by $10^{6}$ ) and divergent wind (vector, unit: $\mathrm{m} \mathrm{s}^{-1}$ ) at surface and $100 \mathrm{~h} \mathrm{hPa} \mathrm{levels} \mathrm{in} \mathrm{(left)} \mathrm{April} \mathrm{of} \mathrm{EOY} \mathrm{and} \mathrm{(right)} \mathrm{May} \mathrm{of} \mathrm{LOY.} \mathrm{Shading}$ indicates significance at the $95 \%$ confidence level for velocity potential or divergent wind. $166 \times 131 \mathrm{~mm}(300 \times 300 \mathrm{DPI})$ 

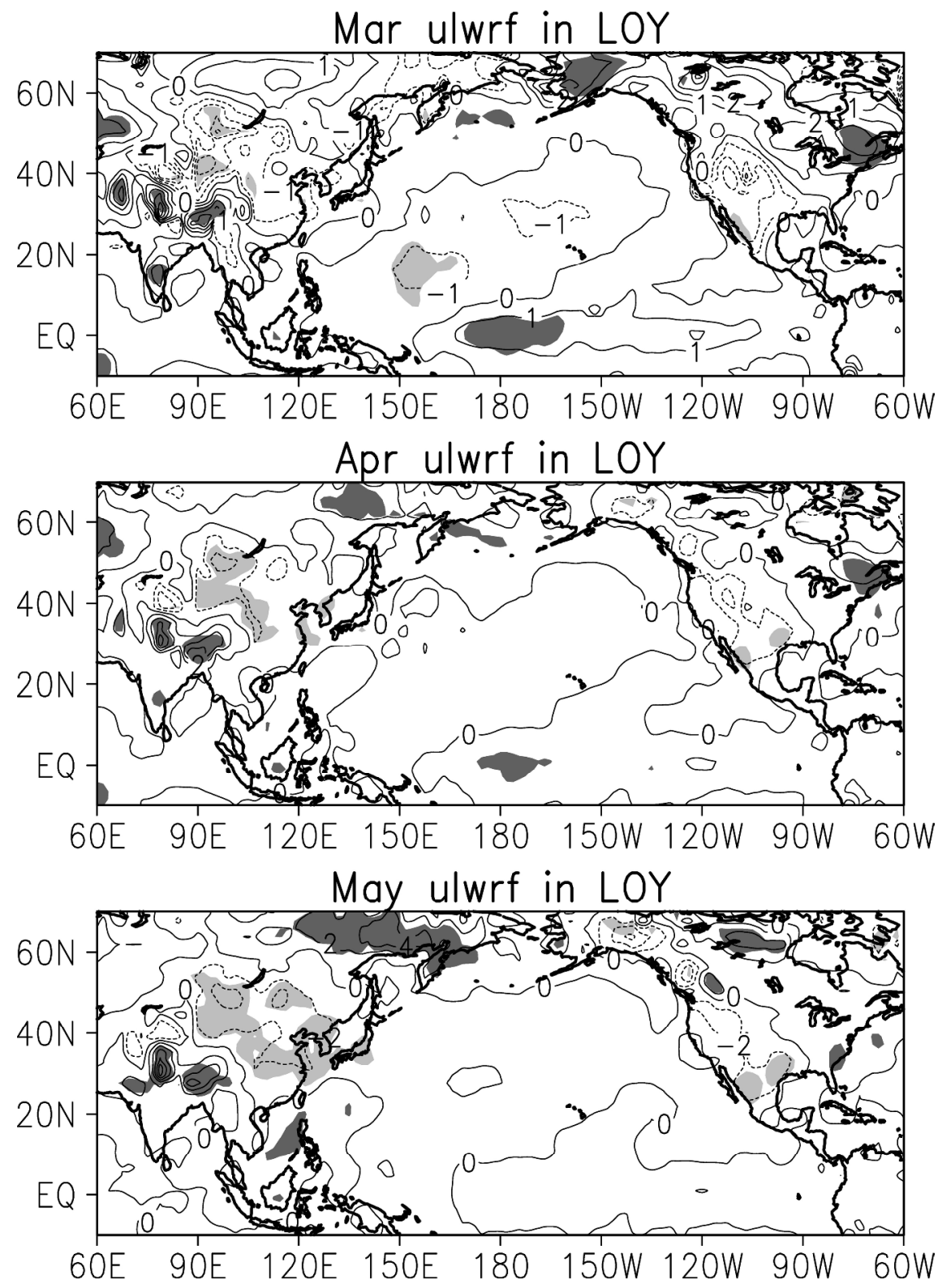

Figure 10. Composite anomalies of upward long-wave radiation flux $\left(\mathrm{W} \mathrm{m}^{-2}\right)$ in LOY. Shading indicates significance at the $95 \%$ confidence level.
$291 \times 402 \mathrm{~mm}(300 \times 300 \mathrm{DPI})$ 